(REVIEW ARTICLE)

\title{
Nanotechnology in food systems: Application and safety
}

\author{
Arafat Shaker Mohamed ${ }^{1}$ and Basuny Amany Mohamed 2,* \\ ${ }^{1}$ Oils \& Fats Research Dept., Food Technology Research Institute, Agricultural Research Center. \\ ${ }^{2}$ Biochemistry Department, Faculty of Agriculture Beni-Suef University, Egypt.
}

Publication history: Received on 16 January 2019; revised on 12 June 2019; accepted on 18 June 2019

Article DOI: https://doi.org/10.30574/wjarr.2019.2.2.0011

\begin{abstract}
Nanotechnology is a multidisciplinary technological and scientific field undergoing a rapid development. In this paper, current applications of nanotechnology in food systems include pesticide delivery systems through bioactive nanencapsulations, biosensors to detect and quantify pathogens, organic compounds, other chemicals and food composition alteration, high-performance sensors and edible thin films to preserve fruit and vegetable. The paper conclude that it is necessary to do a thorough risk assessment of nano foods before they are released to the market.
\end{abstract}

Keywords: Nanotechnology; Nano food; Safety assessment; Nanoparticles

\section{Introduction}

The word nano comes from the Greek for dwarf. A nanometer is thousandth of a thousandth of a thousandth of a meter $\left(10^{-9} \mathrm{~m}\right)$. One nanometer id about 60.000 times smaller than a human hair in diameter or the size of virus, a typical sheet or paper in about $100.000 \mathrm{~m}$ thick, a red blood cell is about 2.000 to $5.000 \mathrm{~nm}$ in size, and the diameter of DNA is in the range of $2.50 \mathrm{~nm}$. Therefore, nanotechnology deals with matter that ranges from one-half the diameter of DNA up to $1 / 20$ the size of red blood cell [1]. Nanotechnology has become one of the most promising technologies to revolutionize conventional food science and the food industry. Nanotechnology assisted processing and packaging has proved its competence in food systems [2]. Different preparation technology could produce nanoparticles with different physical properties. Thus they could be used in food [3]. However, not only is the public perception regarding this new technology uncertain [4], but also the regulation agencies have not yet reached an agreement on worldwide applicable rules [5]. Despite significant debate over the necessity of establishing new regulations for nanotechnology, United States Environmental Safety Agency, National Institute for Occupational Safety and Health, the Food and Drug Administration, the Health and consumer Protection Directorate of the European Commission, International Organization such as the International Organization for Standardization and the Organization for Economic Cooperation and Development, as well as many regulatory respect to the potential risks posed by nanomaterial's [6]. Current scientific regulation of food nanotechnology is characterized by numerous uncertainties regarding risk characteristics. Functionality of food nanotechnology determines its range of applicability and nutritional value of food on the basis of its functions [7]. It is recognized that the biological properties of nanomaterial's largely dependent on their physicochemical parameters. Infact, the major links between nanotechnology and the food industry are enhancing food security, exchanges storage life, improving flavor and nutrient delivery, allowing pathogen, toxin/pesticide detection, and serving functional foods. In this paper, we focus on the aspects of the functionality and applicability of food nanotechnology, and the current progress in their regulation and safety assessment.

\footnotetext{
${ }^{*}$ Corresponding author

E-mail address: dramany_basuny@yahoo.com
} 


\section{Safety assessment}

It is important to note that nanomaterial's,is owing to their increased contact surface area, might have toxic effect in the body that are not apparent in the bulk materials [8]. In addition, there might be potential and unforeseenrisks for their use in food-packaging materials.

Despite this lack of regulation and risk knowledge, a handful of food and nutrition products that contain nanoscale additives are already being sold, such as iron in nutritional drink mixes, micelles that carry vitamins, minerals and phytochemicals in oil, and zinc oxide in breakfast cereals, in addition, nanencapsulations also allows direct contact of nanomaterials with humans through oral intake. SiO2 nanomaterials, one of the most used food nanomaterials, have been studied as carries of fragrances or flavors in food products [9-10]. Lipid-based nanencapsulations systems are also being developed to enhance the performance of antioxidants by improving their solubility and bioavailability [11]. However, the safety of nanencapsulation remains uninvestigated and calls for further risk assessment, particularly for long term toxicity. Nanoscale edible coatings have emerged as an attractive to preserve food quality, extend storage life, and prevent microbial spoilage [12], Allowing direct exposure of humans to nanomaterials. For instance, gelatin-based edible coatings containing cellusenanocrytals, chitosan/nanosilica coatings, chitosan film with nano- Sio2 and alginate/lysozyme nanolaminate coatings have been reported to preserve the quality of fresh foods during extend storage [13]. It should be noted that the ultimate rate and toxicity of nanomaterials in foods and food packaging depend on physicochemical characteristics and dose. Safe application of nanotechnology to the food industry requires through characterization and assessment in silico, in vitro, and in vivo [14]. Altogether, taking into consideration physical forces, asmotic concentration, $\mathrm{pH}$, chemical factors, biological molecules, and commensal microbes, their absorption, distribution, metabolism, excretion, and ultimate toxicity could be quantified and evaluated for risk assessment [14-15].

\section{Types of nanomaterials and nanostructure}

The novel properties of nanomaterials offer many new opportunities for the food industry [16]. Different types of functional nanostructure can be used as building blocks to create novel structures and introduce new functionalities into foods. These include: nanoliposomes, nanoemlsions, nanoparticles and nanofibers. [2] has described several of these structures, their actual and potential uses in food industry. According to the currently available information, nanomaterials used in food applications include both inorganic and organic substances. Engineerednanomaterials are likely to be found in nano foods product fall into three main categories: inorganic, surface functionalized materials, and organic engineered nano materials [17]. Inorganic nanomaterials for application in food, food additives, food packaging or storage include engineered nanomaterials of transition metals, such as silver and iron; alkaline earth metals, such as calcium and magnesium; and non-metals such as selenium and silicates. Other engineered nanomaterials that can potentially be used in food applications include titanium dioxide. Food packaging is the major area of application of metal oxide. Nanosilvers finding a growing use in a number of consumer products, including food and health food, water and food contact surfaces and packaging materials. Indeed, the use of nanosilver as an antimicrobial, antioxidant and a health supplement already surpassed all other engineered nanomaterials currently in use in different sector [18]. Amorphous nanosilica in known to be used in foods contact surfaces and food packaging application. Nanoselenium is being marketed as an additive to a green tea product, with a number of health benefits resulting from enhanced uptake of selenium. Nanocalcium salts are the subject of patent applications for intended use in chewing gums. Nanocalcium and nanomagnesium salts are also available as heath supplement. Nano-iron is available as a health supplement and is used in the treatment of contaminated water, where it is claimed to decontaminate water by breaking down organic pollutants and killing microbial pathogen. A soluble nanomaterial under development is nanosalt. This will enable consumers to cut down their salt intake, since small amounts will cover a larger area of the foods surface. Cola-tasting nanomilk and fat-reduced nano-mayonnaise are just two of the nanotechnology-based food products in Holland [19].

Surface functionalized nanomaterials add certain types of functionality to the matrix, such as antimicrobial activity or a preservative action through absorption of oxygen. For food packaging materials, functionalized engineered nanomaterials are used to bind with the polymer matrix to offer mechanical strength or a barrier against movement of gases, volatile components (such as flavors) or moisture. Compared to internationals, they are more likely to react with different food components, or became bound to food matrices, and hence may not be available for migration from packaging materials. The nanoclay mineral is mainly montmorillobite, which is natural clay obtained from volcanic ash/ricks. Nanoclay has a natural nanoscaled layer structure and is organically to bindto polymer matrices. The use of nanoclays in food packaging can help to develop materials with enhanced gas-barrier properties. 
Organic nanomaterials are used in food, feed improved bioavailability of vitamins, antioxidants in the body, compared to conventional bulk equivalents. A wide range of materials are available in this category, for example food additives (eg, benzoic acid, citric acid, ascorbic acid) and supplements (eg, vitamins A and E, isoflavones, beta-carotene, lutein omega-3 fatty acids and coenzymes Q10). An example of an organic nanomaterial is the tomato carotenoid lycopene [20]. Proteins, fat and sugar molecules, as well as neutraceuticals consisting of food additives derived from plants, are example of organic nanomaterials.

\section{Potential food applications}

All organisms represent a consolidation of various nanoscale-sized objects. Atoms and molecules combine to form dynamic structures and systems that are the building blocks of every organism's existence. For humans, cell membranes, hormones and DNA are examples of vital structures that measure in the nanometer range. In fact, every living organism on earth exists because of the presence and interaction of various nanostructures [21]. Even food molecules such as carbohydrates, proteins and fats are the results of nano-scale level mergers between sugars, amino acids and fatty acids [22]. As it applies to the food industry, nanotechnology involves using biological molecules such as sugar of proteins as target recognition groups for nanostructures that could be used, for example, as biosensors on foods. Such biosensors could serve as detectors of food pathogens and other contaminants and as devices to track food products Figure 1. Nanotechnology may also be used in encapsulation systems for protection against environmental factors. In addition, it can be used in the design of food ingredients such as flavors and antioxidants [23]. Although nanotechnology can potentially be useful in all areas of food production and processing, many of the methods are either a commercial scale. For this reason, nanoscale techniques are most cost effective in the following areas of the food industry, development of new functional materials, food formulations, food processing at microscale and nanoscale levels, product development and storage [24]. Owing to the greater surface area of nanoparticles per mass unit, they are expected to be more biologically active than larger size particle of the same chemical composition. This offers several perspectives for food applications. Nanoparticles can, for instance, be used as bioactive compounds in functional foods [25]. Bioactive compounds that can be found naturally in certain foods have physiological benefits and might help to reduce the risk of certain disease, including cancer. Omega- 3 and omega- 6 fatty acids, probiotics, prebiotics, vitamins and minerals have found their applications in food nanotechnology as bioactive compounds [26]. In the food industry, several novel applications on nanotechnologies have become apparent, including the use of nanoparticle, as well as the development of nanosensors, which are aimed at ensuring food safety [27].

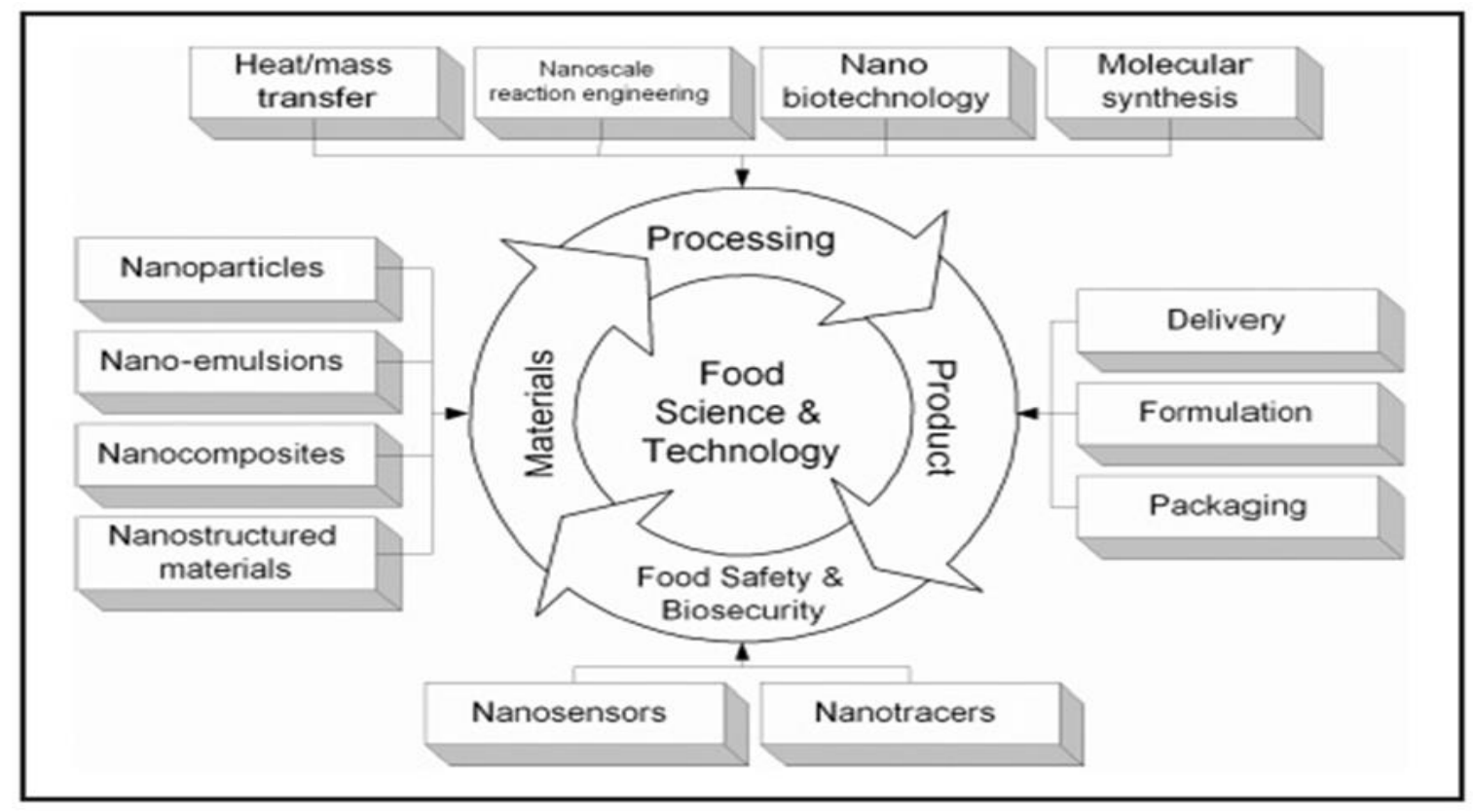

Figure 1 Application matrix of nanotechnology in food science

\section{Analytical food nanotechnology}

The analytical approaches have been subdivided into three groups: Separation techniques, imaging techniques, and characterization techniques. The recent progress made in analytical nanotechnology, as applied to the food industry 
and to food analysis [28]. The electronic nose is a device that uses an array of chemical sensors tied to data-processing system that mimics the way a nose works. A new strategy for feature selection has been introduced to MS-based electronic nose applications [29]. Detection of fruit odors using an electronic nose has been reported [30]. Methods have been reported to estimate chemical and physical properties of pears from the electronic dose signal. The electronic nose could also be a useful and innovative tool to monitor strawberry aroma changes during osmotic dehydration. A typical nanosensor "electronic nose" can be used for quality control of milk during industrial processing. Nanotechnology-based electronic nose applications include: monitoring and control; more accurate volatiles measurement than measuring temperature and the time taken currently in backing to monitor product quality, quality assurance.

Detection and characterization on nano delivery systems are an essential part of understanding the benefits, as well as the potential toxicity of these systems, in food. Scientists showed that for a sufficient characterization, the nano delivery systems need to be separated from the food matrix, for which high performance liquid chromatography or field flow fractionation are the most promising techniques. Subsequently, online photon correlation spectroscopy and mass spectrometry proved a convenient combination of techniques to characterize a wide variety of nano delivery systems [31]. The detection and characteristics of engineered nanoparticle in food has been reported [32].

\section{Nano food}

Nano foods describes food that has been cultivated produced, processed or packaged using nanotechnology techniques or tools, or to which nanofactured, nanomaterials have been added. A nano food has, in fact, been part of food processing for centuries, since many food structures naturally exist at the nanoscale. The purpose of nano food it's to improve food safety, enhance nutrition and flavor and cut costs. Although nano foods is still in its infancy, nanoparticles are now finding application as a carrier of antimicrobial polypeptide required against microbial deterioration of food quality in the food industry. A coating of starch colloids filled with antimicrobial substance, such that if microorganisms grow on the packaged food they will penetrate the starch releasing the antimicrobial agent [33]. The benefits of nano foods, for instance, include health promoting additives, longer shelf-lives or new flavor varieties. The current nanotechnology application in food science providesthe detection of food pathogens, through nanosensors that are quick, sensitive and less labor-intensive procedures.

\section{Compliance with ethical standards}

\section{Acknowledgments}

The authors would like to acknowledge the colleagues who helped us complete this manuscript. We also thank those who gave us moral support during the completion of this manuscript.

\section{Disclosure of conflict of interest}

Authors have declared that no competing interests exist.

\section{References}

[1] Dingman J. (2008). Nanotechnology: its impact on food safety. (Guest Commentary). Journal of Environment Health, 70(6), 47-50.

[2] Weiss J, Takhistov P and McClements, DJ. (2006). Functional materials in food nanotechnology. Journal of Food Science, 71, R107-R116.

[3] Feng T, Xiao Z and Tian H. (2010). Recent patents on nano flavor preparation and its application. Recent Patents on Food, Nutrition \& Agriculture, 2, 243-250.

[4] Bieberstein A, Roosen J, Marette S, Blanchemanche S and Vandermoere F. (2013). Consumer choices for nanofood and nano-packaging in France and Germany. European Review of Agricultural Economics, 40(1), 73-94.

[5] Ravichandran R. (2010). Nanotechnology applications in food and food processing: innovative green approaches, opportunities and uncertainties for global market. International Journal of Green Nanotechnology: Physics and Chemistry, 1, P72-P96. 
[6] Coles D and Frewer J. (2013). Nanotechnology applied to European food production-a review of ethical and regulatory issues. Trends in Food Science \& Technology, 34, 32-43

[7] Srinivas PR, Philbert M, Vu TQ, Huang Q, Kokini JL, Saos E, Chen H, Peterso CM, Friedl K, McDade-Ngutter E, Hubbard C, StarkeReed, VP, Miller N, Betz JM, Dwyer J, Milner J and Ross SA. (2010). Nanotechnology research: applications in nutritional sciences'. Nutrition, 140, 119-124.

[8] Dowling AP. (2004). Development of nanotechnologies. Materialstoday, 7(12), 30-35.

[9] Dekkers S, Krystek P, Peters RJ, Lankveld DX, Bokkers BG, HoevenArentzen PH, Bouwmeester H and Oomen AG. (2011). Presence and risks of nanosilica in food products. Nanotoxicology, 5, 393-405.

[10] Jian A, Ranjan S, Dasgupta N and Ramalingam C. (2018. Nanomaterials in food and agriculture: An overview on their safety concerns and regulatory issues. Journal Critical Reviews in Food Science and Nutrition, 58(2), 297317.

[11] Mozafari MR, Flanagan J, MatiaMerino A, Wati A, Omri A, Suntres ZE and Singh H. (2006). Recent trends in the lipid-based nanoencapsulation of antioxidants and their role in foods. Journal of the Science of Food and Agriculture, 86, 2038-2045.

[12] Medeiros BGS, Souza MP, Pinheiro AC, Bourbon AI, Cerqueira MA, Vicente AA, and Carneiro-da-Cunha MG. (2014). Physical characterization of an alginate/lysozyme nano-laminate coating and its evaluation on 'Coalho' cheese shelf life. Food Bioprocess Technology, 7, 1088-1098.

[13] He X, Aker WG and Hwang HM. (2014). An in vivo study on the photo-enhanced toxicities of S-doped TiO2 nanoparticles to zebra fish embryos (Danio rerio) in terms of malformation, mortality, rheotaxis dysfunction, and DNA damage. Nanotoxicology, 8 (S1), 185-195.

[14] Singh T, Shukla S, Kumar P, Wahla V, Bajpai VK and Rather IR. (2017). Application of nanotechnology in food science: perception and overview. Front Microbiology, 8, 1501-1507.

[15] Cho Y, Kim C, Kim N, Kim C and Park B. (2008). Some cases in applications of nanotechnology to food and agricultural systems. BioChip journal, 2(3), 183-1852.

[16] Chaudhry Q, Scotter M and Blackburn J. (2008). Applications and implications of nanotechnologies for the food sector. Food Additives and Contaminants, 25(3), 241-258.

[17] Woodrow Wilson International Centre for Scholars (2009). The Nanotechnology Consumer Inventory. www.nanotechproject.org; www.wilsoncenter.org

[18] Miller G. (2008). Nanotechnology - the new threat to food Available from Global Research, October 30. https://www.globalresearch.ca/nanotechnology-the-new-threat-to-food/10755

[19] Hoppe PP, Krämer K, Van den Berg H, Steenge G and Van Vliet T. (2003). Synthetic and tomato-based lycopene have identical bioavailability in humans. European Journal of Nutrition, 42(5), 272-278.

[20] Powell M and Colin M. (2008). Nanotechnology and food safety: potential benefits, possible risks. CAB Reviews: Perspectives in Agriculture, Veterinary Science, Nutrition and Natural Resources, 3, 1-6.

[21] Campbell-Platt G. (2009). Food Science and Technology; Food Science and Technology, $2^{\text {nd }}$ Edition. WileyBlackwell: Chichester.

[22] Imafidon GI and Spanier AM. (1994). Unraveling the secret of meat flavor. Trends in Food Science \& Technology, 5, 315- 321.

[23] Nel A, Xia T, Madler L and Li N. (2009). Toxic potential of " materials at the nanolevel. In Progress in Nanotechnology: Applications; Acers, Ed.; Wiley: New York, 2009, 622- 627.

[24] Chen L. (2006). Food protein based materials as neutraceuticals delivery systems. Trends Food Science \& Technology, 17, 272-283.

[25] Watanabe J. (2005). Entrapment of some compounds into biocompatible nano sized particles and their releasing properties. Colloids Surf. B Biointerfaces, 42, 141-146.

[26] Nasongkla N. (2006). Multifunctional polymeric micelles as cancer targeted. MRI ultrasensitive drug delivery systems. Nano Letters, 6, 2427-2430.

[27] Valdés MG, Valdés González AC, Calzón JAG and Díaz-García ME. (2009). Analytical nanotechnology for food analysis. Microchimica Acta, 166(1), 1-19. 
[28] LIobet E, Gualdrón $O$ and Vinaixa M. (2007). Efficient feature selection for mass spectrometry based electronic nose applications. Chemometrics and Intelligent Laboratory Systems, 85(2), 253-261.

[29] Schneider J. (2010). Detection of fruit odors using an electronic nose. http://spie.org/news/0137-detection-offruit-odors-using-an-electronic-nose?SSO=1.

[30] Dion MA, Luykx M, Ruud LM, Peters JB, van Ruth SM and Bouwmeester H. (2008). A review of analytical methods for the identification and characterization of nano delivery systems in food. Journal of Agriculture Food Chemistry, 56(18), 8231-8247

[31] Hentschel A, Gramdorf S, Müller RH and Kurz T. (2008). Beta-carotene-loaded nanostructured lipid carriers. Journal of Food Science, 73(2), N1-N6.

[32] Boumans H. (2010). Release on Command: Bio-switch 4-5. Leads in Life sciences 22/2003TNO Nutrition and Food; Zeist: 2003. www.tno.nl.

\section{How to cite this article}

Arafat SM and Basuny AM. (2019). Nanotechnology in food systems: Application and safety. World Journal of Advanced Research and Reviews, 2(2), 19-24. 